\title{
Association between the longest job and oral health: Japan Gerontological Evaluation Study project cross-sectional study
}

Tatsuo Yamamoto $^{1 *}$, Katsunori Kondo ${ }^{2,3}$, Jun Aida ${ }^{4}$, Shinya Fuchida ${ }^{1}$, Yukio Hirata ${ }^{1}$ and for the JAGES group

\begin{abstract}
Background: Inequality in oral health is a major challenge. Oral diseases and their risk factors accumulate throughout life. The objective of this cross-sectional study was to examine the association of longest job with oral health status and oral health behavior among older Japanese.

Methods: Subjects were a total of 23,191 (11,310 males and 11,881 females) community-dwelling individuals aged 65 or over, living independently and able to perform daily activities from 30 municipalities across Japan. The outcome variables were oral health status (number of teeth, use of denture or bridge and subjective oral health status) and oral health behavior (dental visit for treatment and use of interdental brush or dental floss). The longest job was used as an explanatory variable. Age, educational attainment, equivalent income, and densities of dentists and population in municipalities were used as covariates. Two-level (first level: individual, second level: municipality) multilevel Poisson regression analyses were performed for each sex.

Results: Multilevel Poisson regression analyses showed that all variables of oral health status and oral health behavior were significantly associated with longest job after adjusting for all covariates except denture/bridge use and dental visit for females. People whose longest jobs were sales/service, skilled/labor, agriculture/forestry/fishery or others, or who had no occupation were more likely to have poor oral health status and oral health behavior compared to those whose longest jobs were professional/technical.
\end{abstract}

Conclusions: The longest job may be one of the major determinants of oral health status and oral health behavior in Japanese older people.

Keywords: Longest job, Oral health status, Oral health behavior, Older people, Cross-sectional study

\section{Background}

As oral diseases and their risk factors accumulate throughout the course of life, meaning that inequality in oral health is a major challenge in an aging society [1]. Studies have shown socioeconomic inequalities in oral health status $[2,3]$ and oral health behavior [4] in older people.

Occupation has been used in epidemiological studies as a marker of socioeconomic status [5]. Occupational environment is important for health because people spend long hours at work during their lifetime. Therefore, the oral

\footnotetext{
* Correspondence: yamamoto.tatsuo@kdu.ac.jp

'Department of Dental Sociology, Graduate School of Dentistry, Kanagawa Dental University, Yokosuka, Japan

Full list of author information is available at the end of the article
}

health of older people is affected by work time stress and health care policy in their occupational environment.

In Japan, some municipalities have oral health programs including periodontal examination for adult residents; however, participation rates (3.6\% in 2002) are often not satisfactory [6]. Workplaces are suitable for oral health education and screening of periodontal disease because most of the target population would be involved. However, few workplaces have such systems [7].

Occupational classification is one marker of socioeconomic position and is associated with the health status of older people including the risk of chronic obstructive pulmonary disease [8], subclinical atherosclerosis [9] and chronic disabling pain [10]. Studies using employees in companies suggest gradients of oral health 
status in occupational classification $[11,12]$. However, little is known about the association between occupational classification and oral health status and oral health behavior in older people. Particularly, no studies have been conducted to investigate the association between agriculture/ forestry/fishery workers and oral health in older people.

It is useful for public health decision making and formulating a public health program to identify a target population from the viewpoint of occupational classification. The purpose of this study was to examine the association of the longest job (the job being done for the longest time) with oral health status and oral health behavior using crosssectional data from community-dwelling older Japanese people. As a life-course study showed that low childhood socioeconomic status has a long-lasting negative influence on adult health including oral health [13], educational attainment and current economic status were taken into consideration in the analyses.

\section{Methods}

\section{Study population}

Data from a cross-sectional study, collected as part of the Japan Gerontological Evaluation Study (JAGES) Project, an on-going Japanese prospective cohort study, were used for this study. JAGES aims to conduct empirical studies from gerontological and social epidemiological perspectives. The sample was restricted to those who did not already have a physical or cognitive disability, defined by not receiving public long-term care insurance benefits, at baseline. From July 2010 to January 2012, a mail survey, exceptionally collected by visit in one prefecture, was conducted in a random sample of 169,215 community-dwelling individuals aged 65 years or over residing in 31 municipalities in 12 prefectures in Japan.

The questionnaire on oral health status and oral health behavior was sent to a random sample of 46,009 subjects, of which 27,732 (60.3\%) responded. All subjects in one municipality were excluded because the questions used in the present study were not included in the questionnaire. After excluding 4,541 subjects who did not answer about the longest job held, a total of 23,191 subjects (11,310 males and 11,881 females) aged 65 or older in 30 municipalities were included in the present study.

\section{Outcome variables}

Number of teeth, denture/bridge use and subjective oral health status were evaluated for oral health status, based on a self-administered questionnaire [14]. Respondents were asked to indicate the number of teeth as 20 or more, 10-19, 1-9 or 0. Denture/bridge use was ascertained by asking, "Do you use a denture or bridge?" with possible answers dichotomized into yes and no. Subjective oral health status was ascertained by asking, "How do you rate your oral health (teeth, gum and denture)?" with possible 4 grade answers dichotomized into good and poor.

Oral health behavior was evaluated based on dental visit for treatment and use of an interdental brush or a dental floss. Dental visit for treatment was ascertained by asking, "Did you visit a dentist for treatment (including adjustment of a denture) within 6 months?" with possible answers dichotomized into yes and no. Use of an interdental brush or a dental floss was ascertained by asking, "Do you use an interdental brush or dental floss?" with possible answers dichotomized into yes and no.

\section{Explanatory variable}

Information on the longest job held was used as an explanatory variable and ascertained by asking, "What was the job that you had done for most of your working life?" with possible answers of professional/technical, administrative, clerical, sales/service, skilled/labor, and agriculture/forestry/fishery workers, others and no occupation.

\section{Covariates}

Data on socio-demographics (sex, age, educational attainment, equivalent income) were obtained using a selfadministered questionnaire and used as covariates. To adjust household income for household size, equivalent income was calculated by dividing the household income by the square root of the number of household members, and placed into one of seven categories (less than US $\$ 5,000$, US\$5,000-9,999, US\$10,000-14,999, US\$15,000-19,999, US\$20,000-29,999, US\$30,000-39,999, and US\$4,000,000 or higher) (US\$1 = 100 Japanese yen) [15].

Data on the number of dentists working in hospitals or clinics were obtained from the Survey of Physicians, Dentists and Pharmacists conducted by the Ministry of Health, Labour and Welfare, Japan in 2010. Data on population in 2010 and area of inhabitable land of each municipality (city, town or village) were obtained from the National Population Census Survey conducted by the Ministry of Internal Affairs and Communications, Japan. The number of dentists working in hospitals or clinics per 100,000 people (density of dentists) and population density were calculated for each municipality. The density of dentists was categorized into four groups (lowest, low middle, high middle, or highest) based on 25th, 50th, and 75th percentiles. Population density was categorized into four groups (metropolitan, urban, semi-urban, or rural-agricultural).

\section{Analysis}

The percentage of respondents with poor oral health status and poor oral health behavior were calculated for each longest job in each sex. Two-level (first level: individual, second level: municipality) multilevel Poisson regression models with random intercepts and fixed slopes 
were used separately for males and females to calculate multilevel prevalence ratios (PRs) for the longest job after adjusting for age, educational attainment and equivalent income as individual-level variables and densities of dentists and population as municipality-level variables, with each variable of oral health status or oral health behavior as the outcome. In each model, subjects lacking a outcome variable were excluded from the analysis. However, covariates that included missing data were recorded by reassigning missing values to separate missing categories in order to maximize the number of subjects included in the statistical analysis and thereby maximize statistical power: data lacking information of educational attainment and equivalent income were included as "others or data missing" (the category of missing was combined with that of others) and "data missing" categories, respectively. Moreover, subjects with 20 or more teeth and those with 9 or less teeth were excluded in the models in which denture/ bridge use and use of interdental brush/dental floss were used as outcome variables, respectively, because some subjects with 20 or more teeth and those with 9 or less teeth might not need to use denture/bridge and interdental brush/dental floss, respectively. All statistical analyses were performed using IBM SPSS Statistics 21 (International Business Machines Co., New York, NY, USA) and MLwiN 2.28 (Centre for Multilevel Modelling, University of Bristol, Bristol, UK).

\section{Ethical considerations}

A detailed explanation of the objectives of the JAGES was sent by mail along with the self-administered questionnaire. People who were willing to participate in the study voluntarily completed and mailed back the questionnaire. The JAGES protocol and its informed consent procedure were reviewed and approved by the Ethics Committee on Research of Human Subjects at Nihon Fukushi University.

\section{Results}

Distributions of the subjects in accordance with the longest job, age, educational attainment and equivalent income are shown in Table 1. In males, professional/ technical workers $(23.0 \%)$ followed by skilled/labor workers $(20.9 \%)$ were most predominant; whereas, clerical workers (19.3\%) followed by sales/service workers (18.9\%) were most predominant among females. The percentage of female subjects having no occupation was $12.8 \%$; however, that in males was $1.1 \%$.

Percentages of subjects with poor oral health status and poor oral health behavior are shown in Table 2. The percentage of males having no occupation and agriculture/ forestry/fishery job was the highest in poor oral health status and poor oral health behavior; whereas, those with administrative and clerical job were the lowest. Percentages of females having sales/service, agriculture/forestry/fishery
Table 1 Distributions of the longest job, age, educational attainment and equivalent income in each sex

\begin{tabular}{|c|c|c|c|c|}
\hline & \multicolumn{2}{|c|}{ Male } & \multicolumn{2}{|c|}{ Female } \\
\hline & $\mathbf{N}$ & $\%$ & $\mathbf{N}$ & $\%$ \\
\hline \multicolumn{5}{|l|}{ Longest job } \\
\hline Professional/technical & 2,606 & 23.0 & 1,255 & 10.6 \\
\hline Administrative & 1,305 & 11.5 & 142 & 1.2 \\
\hline Clerical & 1,102 & 9.7 & 2,293 & 19.3 \\
\hline Sales/service & 1,338 & 11.8 & 2,244 & 18.9 \\
\hline Skilled/labor & 2,366 & 20.9 & 1,076 & 9.1 \\
\hline Agriculture/forestry/fishery & 1,186 & 10.5 & 1,204 & 10.1 \\
\hline Others & 1,280 & 11.3 & 2,152 & 18.1 \\
\hline No occupation & 127 & 1.1 & 1,515 & 12.8 \\
\hline \multicolumn{5}{|l|}{ Age group (year old) } \\
\hline $65-69$ & 3,148 & 27.8 & 3,249 & 27.3 \\
\hline $70-74$ & 3,407 & 30.1 & 3,496 & 29.4 \\
\hline $75-79$ & 2,562 & 22.7 & 2,596 & 21.9 \\
\hline $80-84$ & 1,498 & 13.2 & 1,582 & 13.3 \\
\hline 85 or older & 695 & 6.1 & 958 & 8.1 \\
\hline \multicolumn{5}{|l|}{ Educational attainment (year) } \\
\hline Less than 6 & 279 & 2.5 & 519 & 4.4 \\
\hline $6-9$ & 4,739 & 41.9 & 5,462 & 46.0 \\
\hline $10-12$ & 3,625 & 32.1 & 4,041 & 34.0 \\
\hline 13 or longer & 2,483 & 22.0 & 1,590 & 13.4 \\
\hline Others or data missing & 184 & 1.6 & 269 & 2.3 \\
\hline \multicolumn{5}{|l|}{ Equivalent income (US\$) } \\
\hline Less than 5,000 & 386 & 3.4 & 778 & 6.5 \\
\hline $5,000-9,999$ & 1,038 & 9.2 & 1,424 & 12.0 \\
\hline $10,000-14,999$ & 1,350 & 11.9 & 1,295 & 10.9 \\
\hline $15,000-19,999$ & 2,240 & 19.8 & 1,776 & 14.9 \\
\hline $20,000-29,999$ & 2,459 & 21.7 & 2,056 & 17.3 \\
\hline $30,000-39,999$ & 1,452 & 12.8 & 1,274 & 10.7 \\
\hline 40,000 or higher & 1,035 & 9.2 & 941 & 7.9 \\
\hline Data missing & 1,350 & 11.9 & 2,337 & 19.7 \\
\hline
\end{tabular}

job and no occupation were the highest in poor oral health status and poor oral health behavior; whereas, those having professional/technical, administrative and clerical job were the lowest.

Multilevel PRs of the longest job in each sex after adjusting for individual-level age, educational attainment and equivalent income, and municipality-level densities of dentists and population are shown in Table 3. Significantly high PRs for some kinds of longest jobs were observed in all variables of oral health status and all variables of oral health behavior except denture/bridge use and dental visit for treatment in females. Especially, agriculture/forestry/fishery workers showed significantly 
Table 2 Total number of subjects for analyses and percentages of subjects with poor oral health status and poor oral health behavior according to the longest job in each sex

\begin{tabular}{|c|c|c|c|c|c|c|c|c|c|c|}
\hline \multirow[t]{3}{*}{ Longest job in each sex } & \multicolumn{6}{|c|}{ Poor oral health status } & \multicolumn{4}{|c|}{ Poor oral health behavior } \\
\hline & \multicolumn{2}{|c|}{$\begin{array}{l}\text { Having } 19 \text { or } \\
\text { less teeth }\end{array}$} & \multicolumn{2}{|c|}{$\begin{array}{l}\text { Denture/bridge } \\
\text { non-user in subjects } \\
\text { with } 19 \text { or less teeth }\end{array}$} & \multicolumn{2}{|c|}{$\begin{array}{l}\text { Subjective poor } \\
\text { oral health }\end{array}$} & \multicolumn{2}{|c|}{$\begin{array}{c}\text { No dental visit for } \\
\text { treatment }\end{array}$} & \multicolumn{2}{|c|}{$\begin{array}{l}\text { Interdental brush/ } \\
\text { dental floss non- } \\
\text { user in subjects with } \\
10 \text { or more teeth }\end{array}$} \\
\hline & $\mathrm{N}$ for analyses & $\%$ & $\mathrm{~N}$ for analyses & $\%$ & $\mathrm{~N}$ for analyses & $\%$ & $\mathrm{~N}$ for analyses & $\%$ & $\mathrm{~N}$ for analyses & $\%$ \\
\hline \multicolumn{11}{|l|}{ Male } \\
\hline Professional/technical & 2,555 & 60.2 & 1,453 & 29.2 & 2,506 & 31.0 & 2,514 & 46.7 & 1,402 & 44.9 \\
\hline Administrative & 1,281 & 57.5 & 701 & 25.8 & 1,256 & 24.5 & 1,269 & 40.7 & 755 & 43.8 \\
\hline Clerical & 1,089 & 60.7 & 635 & 23.9 & 1,071 & 27.6 & 1,083 & 43.2 & 645 & 46.0 \\
\hline Sales/service & 1,318 & 68.5 & 837 & 33.3 & 1,282 & 31.0 & 1,290 & 45.5 & 705 & 49.5 \\
\hline Skilled/labor & 2,313 & 69.6 & 1,487 & 35.8 & 2,251 & 34.4 & 2,263 & 54.0 & 1,057 & 51.0 \\
\hline Agriculture/forestry/fishery & 1,154 & 84.1 & 854 & 39.9 & 1,122 & 34.0 & 1,114 & 55.7 & 354 & 56.2 \\
\hline Others & 1,238 & 71.1 & 787 & 40.2 & 1,200 & 33.2 & 1,201 & 51.9 & 536 & 53.7 \\
\hline No occupation & 123 & 80.5 & 89 & 44.9 & 118 & 45.8 & 116 & 67.2 & 46 & 63.0 \\
\hline Total & 11,071 & 66.8 & 6,843 & 33.1 & 10,806 & 31.3 & 10,850 & 48.7 & 5,500 & 48.4 \\
\hline \multicolumn{11}{|l|}{ Female } \\
\hline Professional/technical & 1,224 & 57.2 & 648 & 31.0 & 1,203 & 24.0 & 1,204 & 47.6 & 770 & 31.9 \\
\hline Administrative & 132 & 68.9 & 82 & 29.3 & 132 & 22.0 & 132 & 50.8 & 57 & 28.1 \\
\hline Clerical & 2,244 & 56.6 & 1,169 & 29.6 & 2,209 & 25.3 & 2,217 & 47.9 & 1,363 & 30.9 \\
\hline Sales/service & 2,155 & 69.1 & 1,331 & 32.3 & 2,131 & 32.1 & 2,132 & 52.8 & 1,046 & 38.8 \\
\hline Skilled/labor & 1,045 & 69.7 & 654 & 33.3 & 1,027 & 28.8 & 1,033 & 56.4 & 496 & 42.1 \\
\hline Agriculture/forestry/fishery & 1,156 & 85.8 & 848 & 31.8 & 1,165 & 29.3 & 1,149 & 60.0 & 344 & 48.5 \\
\hline Others & 2,084 & 74.5 & 1,366 & 34.8 & 2,042 & 29.8 & 2,036 & 55.0 & 865 & 44.3 \\
\hline No occupation & 1,465 & 76.0 & 997 & 35.9 & 1,448 & 29.3 & 1,426 & 57.8 & 569 & 40.4 \\
\hline Total & 11,505 & 69.0 & 7,095 & 32.7 & 11,357 & 28.4 & 11,329 & 53.3 & 5,510 & 37.7 \\
\hline
\end{tabular}

higher PRs in having 19 or less teeth $(1.15,95 \%$ confidence interval $(\mathrm{CI}): 1.06$ - 1.26), denture/bridge nonusers in subjects with 19 or less teeth $(1.18,1.01-1.36)$ and interdental brush/dental floss non-user in subjects with 10 or more teeth $(1.21,1.03$ - 1.43) in males, and having 19 or less teeth $(1.21,1.09-1.34)$ and interdental brush/dental floss non-user in subjects with 10 or more teeth $(1.25,1.02-1.53)$ in females.

The municipality-level density of dentists was significantly associated with subjective oral health and dental visit for treatment in females in the fully adjusted models. Subjects in municipalities with a lower density of dentists were less likely to have subjective poor oral health and visit dentists. Municipality-level population density was significantly associated with the number of teeth and dental visit for treatment in females. Subjects in municipalities with lower population density were less likely to have 20 or more teeth and visit dentists.

\section{Discussion}

The results of the present study showed that the longest job held was significantly associated with oral health status and oral health behavior in older Japanese people even after adjusting for individual-level age, educational attainment (childhood socioeconomic status) and equivalent income (current socioeconomic status) and municipalitylevel differences in densities of dentists and population (environment related to access to dental care). Especially, older people whose longest jobs were sales/service, skilled/ labor, agriculture/forestry/fishery or others, or who had no occupation were more likely to have poor oral health status and poor oral health behavior compared to those whose longest jobs were professional/technical.

The results of present study agree with those of previous studies $[11,12,16]$. Studies in Japanese male workers aged 20-69 years showed that professional and office workers had better oral health including periodontal status and number of teeth than salespersons and service occupations $[11,12]$. A study from Denmark among 75-year-olds, in which the longest job held was categorized into unskilled workers, skilled workers, low managerials, high managerials and others, showed that unskilled workers had significantly higher odds ratios for having no or few teeth than high managerials and others after adjusting for 
Table 3 Fully adjusted multilevel prevalence ratios for the longest job in each sex

\begin{tabular}{|c|c|c|c|c|c|c|c|c|c|c|}
\hline \multirow{3}{*}{ Longest job in each sex } & \multicolumn{6}{|c|}{ Poor oral health status } & \multicolumn{4}{|c|}{ Poor oral health behavior } \\
\hline & \multicolumn{2}{|c|}{$\begin{array}{l}\text { Having } 19 \text { or less } \\
\text { teeth }\end{array}$} & \multicolumn{2}{|c|}{$\begin{array}{c}\text { Denture/bridge } \\
\text { non-user in subjects } \\
\text { with } 19 \text { or less teeth }\end{array}$} & \multicolumn{2}{|c|}{$\begin{array}{l}\text { Subjective poor } \\
\text { oral health }\end{array}$} & \multicolumn{2}{|c|}{$\begin{array}{l}\text { No dental visit for } \\
\text { treatment }\end{array}$} & \multicolumn{2}{|c|}{$\begin{array}{l}\text { Interdental brush/dental } \\
\text { floss non-user in subjects } \\
\text { with } 10 \text { or more teeth }\end{array}$} \\
\hline & PR & $95 \% \mathrm{Cl}$ & PR & $95 \% \mathrm{Cl}$ & PR & $95 \% \mathrm{Cl}$ & PR & $95 \% \mathrm{Cl}$ & PR & $95 \% \mathrm{Cl}$ \\
\hline \multicolumn{11}{|l|}{ Male } \\
\hline Administrative & 1.01 & $(0.92-1.10)$ & 1.00 & $(0.84-1.20)$ & 0.85 & $(0.74-0.97)^{*}$ & 0.91 & $(0.82-1.01)$ & 1.02 & $(0.89-1.17)$ \\
\hline Clerical & 1.02 & $(0.93-1.12)$ & 0.88 & $(0.73-1.06)$ & 0.92 & $(0.80-1.05)$ & 0.94 & $(0.84-1.05)$ & 1.04 & $(0.91-1.20)$ \\
\hline Sales/service & 1.11 & $(1.02-1.21)^{*}$ & 1.08 & $(0.93-1.26)$ & 0.98 & $(0.86-1.10)$ & 0.97 & $(0.88-1.07)$ & 1.08 & $(0.95-1.24)$ \\
\hline Skilled/labor & 1.07 & $(1.00-1.15)$ & 1.11 & $(0.98-1.27)$ & 1.08 & $(0.98-1.20)$ & 1.13 & $(1.04-1.23)^{* *}$ & 1.08 & $(0.96-1.22)$ \\
\hline Agriculture/forestry/fishery & 1.15 & $(1.06-1.26)^{* *}$ & 1.18 & $(1.01-1.36)^{*}$ & 1.10 & $(0.96-1.25)$ & 1.10 & $(1.00-1.22)$ & 1.21 & $(1.03-1.43)^{*}$ \\
\hline Others & 1.07 & $(0.98-1.16)$ & 1.23 & $(1.06-1.42)^{* *}$ & 1.05 & $(0.93-1.18)$ & 1.08 & $(0.97-1.19)$ & 1.15 & $(0.99-1.32)$ \\
\hline No occupation & 1.09 & $(0.89-1.34)$ & 1.31 & $(0.94-1.82)$ & 1.41 & $(1.06-1.87)^{*}$ & 1.30 & $(1.03-1.64)^{*}$ & 1.32 & $(0.91-1.93)$ \\
\hline \multicolumn{11}{|l|}{ Female } \\
\hline Administrative & 1.16 & $(0.93-1.45)$ & 1.00 & $(0.66-1.54)$ & 0.94 & $(0.64-1.38)$ & 1.07 & $(0.83-1.39)$ & 0.87 & $(0.53-1.45)$ \\
\hline Clerical & 1.01 & $(0.92-1.11)$ & 0.99 & $(0.83-1.18)$ & 1.06 & $(0.92-1.23)$ & 1.04 & $(0.94-1.16)$ & 0.97 & $(0.83-1.14)$ \\
\hline Sales/service & 1.15 & $(1.05-1.26)^{* *}$ & 0.99 & $(0.84-1.18)$ & 1.29 & $(1.12-1.48)^{* * *}$ & 1.06 & $(0.96-1.17)$ & 1.15 & $(0.97-1.35)$ \\
\hline Skilled/labor & 1.10 & $(0.99-1.22)$ & 1.00 & $(0.82-1.22)$ & 1.13 & $(0.96-1.33)$ & 1.10 & $(0.98-1.24)$ & 1.14 & $(0.94-1.38)$ \\
\hline Agriculture/forestry/fishery & 1.21 & $(1.09-1.34)^{* * *}$ & 0.95 & $(0.79-1.15)$ & 1.16 & $(0.99-1.37)$ & 1.04 & $(0.93-1.17)$ & 1.25 & $(1.02-1.53)^{*}$ \\
\hline Others & 1.15 & $(1.05-1.26)^{* *}$ & 1.03 & $(0.87-1.22)$ & 1.18 & $(1.02-1.36)^{*}$ & 1.06 & $(0.96-1.18)$ & 1.23 & $(1.05-1.46)^{*}$ \\
\hline No occupation & 1.13 & $(1.03-1.25)^{*}$ & 1.11 & $(0.93-1.33)$ & 1.19 & $(1.02-1.39)^{*}$ & 1.10 & $(0.99-1.23)$ & 1.14 & $(0.94-1.37)$ \\
\hline
\end{tabular}

$\mathrm{PR}$, prevalence ratio; $\mathrm{Cl}$, confidence interval.

Reference: professional/technical.

Adjusted for individual-level age, educational attainment and equivalent income, and municipality-level densities of dentists and population.

${ }^{*}: P<0.05,{ }^{* *}: P<0.01,{ }^{* * *}: P<0.001$.

income and education [16]. In addition to support the results of the previous studies, the present study added new findings including that agriculture/forestry/fishery job was one of the occupational classes associated with poor oral health status and poor oral health behavior.

Sex differences were observed in the association between the longest job held and some variables of oral health status and oral health behavior. However, no statistically significant differences in the longest job held were observed in denture/bridge use in females after adjusting for individual-level age, education and income, and municipality-level densities of dentists and population. A significant association was observed between low income and not using denture/bridge (data not shown). These results suggest that the difference in denture/ bridge use was ascribed to differences in the present economic status but not the longest job in females. Denture/bridge treatment is covered by insurance in Japan; however, $10-30 \%$ of the treatment fee is out-ofpocket. Therefore, the financial aspect of dental treatment should be considered in order to reduce oral health inequalities especially in females.

There are several possible pathways between the longest job held and oral health status and oral health behavior. One possibility is that temporal accessibility to dental health care varies according to occupational classification. For example, professional workers could manage their schedule by themselves and could easily gain access to dental health care. However, sales/service and skilled/labor workers may have a lesser degree of time flexibility than professional workers. In addition to the time flexibility according to the longest job, present working situation according to the longest job may affect denture/bridge use and dental visit. The percentage of subjects who still work was highest in agriculture/forestry/fishery workers ( $47 \%$ for males, $36 \%$ for females). Because agriculture/forestry/fishery workers still work, they might have less chance to visit dentists and receive denture treatment.

A second possibility is that spatial accessibility differs among the job type. Agriculture/forestry/fishery workers live in rural areas. On the other hand, professional/technical workers live in urban areas. The density of dental clinics is higher in urban areas than rural areas in Japan, especially in the period when the study subjects were engaged in their longest job [17]. A study showed that the density of dentists was associated with having a regular dentist in Japan even where universal healthcare insurance covered dental care [18]. Fully adjusted models in the present study showed that densities of dentists and 
population were significantly associated with some variables of oral health status and oral health behavior. As even after adjusting for densities of dentists and population, the longest job held was associated with oral health status, the longest job itself might be a significant determinant of oral health status.

The third possibility is that the perceived need of dental health varies according to job type. For example, professional/technical, administrative or clerical workers are more likely to pay attention to their appearance and speech, which are affected by the front teeth, than agriculture/forestry/fishery workers and people without an occupation. The fourth possibility is that the chance to participate in an oral health program and to obtain information of oral health varies among the longest jobs. Oral health programs including dental check-up are not mandated by law in Japan. Large companies have their own oral health program; however, small companies and small municipalities where agriculture/forestry/fishery workers live do not [19].

The strengths of the present study include large sample size, population-based sampling, and control for potential confounding factors. However, the present study also has a number of limitations. First, measurement of oral health status was based on self-report, not based on clinical examination. However, the validity and reliability of the self-reported number of teeth and denture-bridge use has been established by multiple studies and widely used in epidemiological surveys [20]. We have confirmed the validity of our questionnaire for oral health status [14]. Second, data on the longest job held were also obtained using a self-administered questionnaire. However, the validity of the measure was reported [21]. Third, duration spent in the longest job was unknown. For example, housewives who worked in a technical field for a year before marriage were counted as "technical workers" rather than no occupation even if the non-working period was longer than the working period. A further study considering the duration is needed to confirm the results of the present study. Fourth, the characteristics of the analyzed population might not represent that of the target population. Because demographic data on the target population were not obtained, we could not evaluate representativeness of the analyzed population. Our previous study, which was done in 2003 in one municipality using the same survey method (response rate: $55.5 \%$ ), showed that people under the age of 80 and with middle to high levels of household income were more likely to respond to a questionnaire survey [22].

\section{Conclusions}

The longest job held was significantly associated with oral health status and oral health behavior in older Japanese people even after adjusting for individual-level age, educational attainment and equivalent income, and municipality-level densities of dentists and population. Especially, older people whose longest jobs were sales/ service, skilled/labor, agriculture/forestry/fishery or others, or who had no occupation were more likely to have poor oral health status and poor oral health behavior compared to those whose longest jobs were professional/technical. These results suggest that intervention in people whose jobs were sales/service, skilled/labor, agriculture/forestry/ fishery or others, or who had no occupation may help reduce inequality in oral health due to job classification.

\section{Abbreviations}

JAGES: Japan Gerontological Evaluation Study; PR: Prevalence ratio; $\mathrm{Cl}$ : Confidence interval.

\section{Competing interests}

The authors declare that they have no competing interests.

\section{Authors' contributions}

TY conceived the idea for the study, participated in its design, performed the statistical analysis and drafted the manuscript as the principal author. KK is the principal investigator of the JAGES project, helped to develop the idea of the study, participated in acquiring the data and the study design, and edited the manuscript. JA participated in data acquisition and study design and critically revised the manuscript. SF helped with data analysis and critically revised the manuscript. YH helped to develop the idea of the study, participated in the study design, and edited the manuscript. All authors read and approved the final manuscript.

\section{Acknowledgements}

The authors would like to express their gratitude to Ms. Nao Okada, public health nurse at the Kobe City Health Center, Kobe, Japan for valuable advice. This study used data from the Japan Gerontological Evaluation Study (JAGES), conducted by the Center for Well-being and Society, Nihon Fukushi University as one of their research projects. This study was supported in part by Health Labour Sciences Research Grant, Comprehensive Research on Aging and Health (H24-Junkanki (Seisyu)-Ippan-007) from the Japanese Ministry of Health, Labour and Welfare (MHLW), and Grant-in-Aid for Scientific Research (KAKENHI 23243070) from the Japan Society for the Promotion of Science.

\section{Author details}

${ }^{1}$ Department of Dental Sociology, Graduate School of Dentistry, Kanagawa Dental University, Yokosuka, Japan. ${ }^{2}$ Center for Preventive Medical Science, Chiba University, Chiba, Japan. ${ }^{3}$ Center for Well-being and Society, Nihon Fukushi University, Nagoya, Japan. ${ }^{4}$ Department of International and Community Oral Health, Tohoku University Graduate School of Dentistry, Sendai, Japan.

Received: 15 August 2014 Accepted: 17 October 2014

Published: 27 October 2014

\section{References}

1. Tsakos G: Inequalities in oral health of the elderly: rising to the public health challenge? J Dent Res 2011, 90:689-690.

2. Tsakos G, Sheiham A, lliffe S, Kharicha K, Harari D, Swift CG, Gillman G, Stuck AE: The impact of educational level on oral health-related quality of life in older people in London. Eur J Oral Sci 2009, 117:286-292.

3. Tsakos G, Demakakos P, Breeze E, Watt RG: Social gradients in oral health in older adults: findings from the English longitudinal survey of aging. Am J Public Health 2011, 101:1892-1899.

4. Listl S: Income-related inequalities in dental service utilization by Europeans aged 50+. J Dent Res 2011, 90:717-723.

5. Ben-Shlomo Y, Kuh D: A life course approach to chronic disease epidemiology: conceptual models, empirical challenges and interdisciplinary perspectives. Int J Epidemio/ 2002, 31:285-293.

6. Aoyama $\mathrm{H}$, Ando $\mathrm{Y}, \mathrm{Hanada} \mathrm{N}$ : The receiving rate of oral examination for periodontitis based on the health law for elderly. Health Sci Health Care 2004, 4:42-43 (in Japanese) 
7. Kimura H, Goda K, Takeda N, Hirao T, Fukunaga I, Kageyama H, Jitsunari F: Oral health promotion in the workplace and relative factors. J Dent Hith 2001, 51:37-47 (in Japanese).

8. Miravitlles M, Naberan K, Cantoni J, Azpeitia A: Socioeconomic status and health-related quality of life of patients with chronic obstructive pulmonary disease. Respiration 2011, 82:402-408.

9. Nash SD, Cruickshanks KJ, Klein R, Klein BE, Nieto FJ, Ryff CD, Krantz EM, Shubert CR, Nondahl DM, Acher CW: Socioeconomic status and subclinical atherosclerosis in older adults. Prev Med 2011, 52:208-212.

10. Lacey RJ, Belcher J, Croft PR: Does life course socio-economic position influence chronic disabling pain in older adults? A general population study. Eur J Public Health 2013, 23:534-540.

11. Morita I, Nakagaki H, Yoshii S, Tsuboi S, Hayashizaki J, Mizuno K, Sheiham A: Is there a gradient by job classification in dental status in Japanese men? Eur J Oral Sci 2007, 115:275-279.

12. Morita I, Nakagaki H, Yoshii S, Tsuboi S, Hayashizaki J, Igo J, Mizuno K, Sheiham A: Gradients in periodontal status in Japanese employed males. J Clin Periodontol 2007, 34:952-956.

13. Poulton R, Caspi A, Milne BJ, Thomson WM, Taylor A, Sears MR, Moffitt TE: Association between children's experience of socioeconomic disadvantage and adult health: a life-course study. Lancet 2002, 360:1640-1645.

14. Yamamoto T, Kondo K, Fuchida S, Aida J, Nakade M, Hirata Y: Validity of self-reported oral health variables: Aichi Gerontological Evaluation Study (AGES) project. Health Sci Health Care 2012, 12:4-12 (in Japanese).

15. Matsuyama Y, Aida J, Takeuchi K, Tsakos G, Watt RG, Kondo K, Osaka K: Inequalities of dental prosthesis use under universal healthcare insurance. Community Dent Oral Epidemiol 2014, 42:122-128.

16. Avlund $\mathrm{K}$, Holstein BE, Osler M, Damsgaard MT, Holm-Pedersen P, Rasmussen NK: Social position and health in old age: the relevance of different indicators of social position. Scand J Public Health 2003, 31:126-136

17. Okawa Y, Hirata S, Okada M, Ishii T: Geographic distribution of dentists in Japan: 1980-2000. J Public Health Dent 2011, 71:236-240.

18. Hanibuchi T, Aida J, Nakade M, Hirai H, Kondo K: Geographical accessibility to dental care in the Japanese elderly. Community Dent Health 2011, 28:128-135.

19. Ishii M, Komatsuzaki A, Suetaka T, lida H: Relations between dental care expenses and dental health services carried out by health insurance associations. Jpn J Dent Pract Admin 1999, 34:58-66 (in Japanese).

20. Pitiphat W, Garcia Rl, Douglass CW, Joshipura KJ: Validation of self reported oral health measures. J Public Health Dent 2002, 62:122-128.

21. Lacey RJ, Belcher J, Croft PR: Validity of two simple measures for estimating life-course socio-economic position in cross-sectional postal survey data in an older population: results from the North Staffordshire Osteoarthritis Project (NorStOP). BMC Med Res Methodol 2012, 12:88,

22. Suemori K: Tendency to non-response. In Health Inequalities in Japan: An Empirical Study of Older People. Edited by Kondo K. Melbourne, Australia: Trans Pacific Press; 2010:222.

doi:10.1186/1472-6831-14-130

Cite this article as: Yamamoto et al:: Association between the longest job and oral health: Japan Gerontological Evaluation Study project cross-sectional study. BMC Oral Health 2014 14:130.

\section{Submit your next manuscript to BioMed Central and take full advantage of:}

- Convenient online submission

- Thorough peer review

- No space constraints or color figure charges

- Immediate publication on acceptance

- Inclusion in PubMed, CAS, Scopus and Google Scholar

- Research which is freely available for redistribution

Submit your manuscript at www.biomedcentral.com/submit
C Biomed Central 